\title{
Energy Distribution in the Spectra of Carbon Stars
}

\author{
JANIS-IMANTS STRAUME \\ Radioastrophysical Observatory, Riga, Latvia
}

Carbon stars have a special evolutionary state among cool giants because of the peculiarity of their chemical composition. Spectra of these stars have a very composite structure with a variety of molecular bands.

We have calculated the energy distribution in the spectra of carbon stars on the basis of model atmospheres. The standard opacity sources in the continuum were taken into account as well as absorption in electronic-vibration bands of the molecules $\mathrm{CN}, \mathrm{C}_{2}, \mathrm{CH}, \mathrm{CS}, \mathrm{SiS}, \mathrm{SiH}, \mathrm{SiO}, \mathrm{CaCl}, \mathrm{MgH}, \mathrm{AlH}$, and $\mathrm{ZrO}$. 